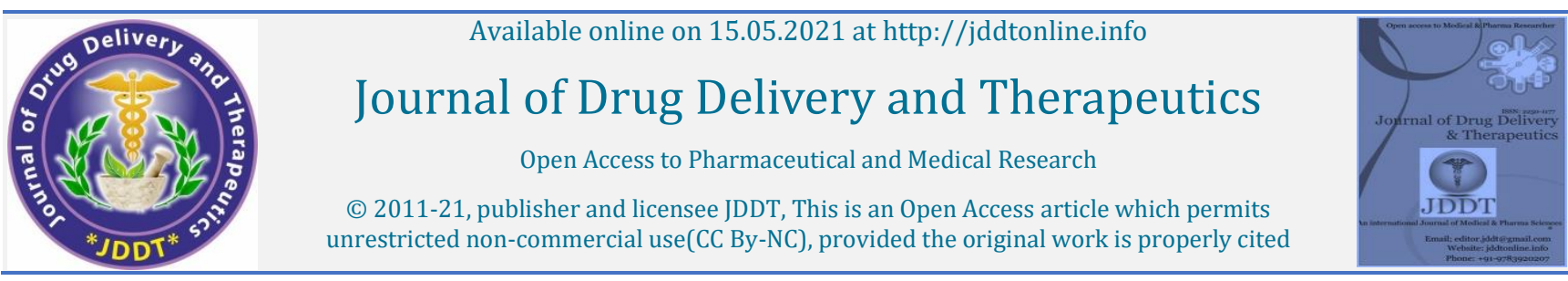

(C) 2011-21, publisher and licensee JDDT, This is an Open Access article which permits Open Access Full Text Article

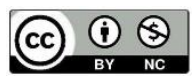

Review Article

\title{
Phytosome as a Novel Drug Delivery System for Bioavailability Enhancement of Phytoconstituents and its Applications: A Review
}

\author{
Gaikwad Abhijeet R ${ }^{1 *}$, Ahire Komal D 2 , Gosavi Aachal A1 , Salunkhe K S ${ }^{1}$, Khalkar Aditi ${ }^{1}$ \\ ${ }^{1 *}$ Department of Pharmaceutics, Sanjivani College of Pharmaceutical Education and Research Kopargaon, India \\ ${ }^{2}$ MGV'S Pharmacy College, Panchavati, Nashik, India
}

\section{Article Info:}

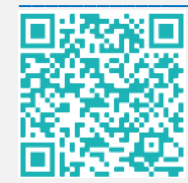

\section{Article History:}

Received 19 March 2021; Review Completed 27 April 2021 Accepted 03 May 2021; Available online 15 May 2021

Cite this article as:

Gaikwad AR, Ahire KD, Gosavi AA, Salunkhe KS, Khalkar A, Phytosome as a Novel Drug Delivery System for Bioavailability Enhancement of Phytoconstituents and its Applications: A Review Journal of Drug Delivery and Therapeutics. 2021; 11(3):138-152

DOI: http://dx.doi.org/10.22270/jddt.v11i3.4847

*Address for Correspondence:

Gaikwad Abhijeet R, Department of Pharmaceutics, Sanjivani College of Pharmaceutical Education and

Research Kopargaon, India

\section{Abstract}

Phytoconstituents are used extensively in modern science due to their varied therapeutic actions with few side effects. Regardless of their excellent pharmacodynamic activity, many Phytoconstituents have shown less bioavailability in vivo. Novel drug delivery systems have gained vital importance due to their increased bioavailability, and overall therapeutics. The water miscible Phytoconstituents have excellent bioactivity in vitro, however poor or no action in vivo. Phytosome technology can overcome this drawback during which the Phyto actives are allowed to react with phospholipid molecules. The Phytoconstituents with low lipoid solubility on complexation into herbal extract. Phospholipids show high affinity for polyphenolics, and type supramolecular adducts having a certain ratio. Hydrogen bond interactions between Phytoconstituents and phospholipids enable phospholipid complexes as an integral part. Complexation of phospholipids with active constituents of plants improves their bioavailability and is being extensively studied by researchers, and additional research during this regard is predicted within the future. This review highlights the unique property of phospholipids in drug delivery, phospholipid chemistry, stoichiometric ratios. We also discuss recent progress in research on the preparation, characterization, structural verification, advantages, recent patents, marketed formulation their application to enhance the bioavailability of active herbal Phytoconstituents.

Keywords: Phytosome, Novel drug delivery, Phosphatidylcholine, Bioavailability, Patents, Applications.

\section{Abbreviations:}

NDDS: Novel drug delivery system.

PC: Phosphatidylcholine.

PE: Phosphatidylethanolamine.

PI: Phosphatidylinositol.

PA: Phosphatidic acid.

PS: Phosphatidylserine.

GPL: Glycerophospholipids.

CL: Cardiolipin.

SM: Sphingomyelin.

LPC: Lyso-Phosphatidylcholine.

TLC: Thin layer liquid chromatography.

HPLC: High - performance liquid chromatography.

EVO: Evodiamine.

LDL: Low-density lipoprotein.

THF: Tetrahydrofuran.

RBF: Round bottom flask.

SCF: Super critical fluids.
SAS: Supercritical anti-solvent.

RESS: Rapid expansion of supercritical solutions.

GAS: Gas anti-solvent technique.

SEDS: Solution enhanced dispersion by supercritical fluids.

LPC: Luteolin phospholipid complex.

GalN/LPS: Galactosamine and hepatic-induced lipopolysaccharide.

AUC: Area under curve.

GBE: Ginkgobiloba extract.

GBP: Ginkgobiloba phytosome.

TEM: Transmission Electron Microscopy.

PCS: Photon correlation Spectroscopy.

NMR: Nuclear Magnetic Resonance.

DL: Double layer.

SEM: Scanning Electron Microscopy.

DSC: Differential Scanning calorimetry

FTIR: Fourier transform infrared spectroscopy.

XRD: X-ray diffraction. 


\section{INTRODUCTION:}

Novel drug delivery system is a novel approach to drug delivery that addresses the constraints of the standard drug delivery systems. India is a country has a huge knowledge base of Ayurveda whose potential is only being realized within the recent years. However, the drug delivery system used for administering the herbal medicine to the patient is ancient and out-of-date, leading to reduced effectiveness of the drug. If the novel drug delivery technology is applied in herbal drugs, it should help in increasing the effectiveness and reducing the side effects of varied herbal compounds and herbs. this is the fundamental plan behind incorporating novel technique of drug delivery in herbal medicines. 1.Phyto-phospholipid complex (phytosome) is a novel approach of drug delivery system, and it's advantageous in delivering the herbal drug at a predetermined rate, delivery of drug at the site of action, minimizes the harmful effects, increase in bioavailability of medication, control of the distribution of drug is achieved by incorporate the drug in carrier system or in changing the structure of the drug at a molecular level, herbal drug has become additional widespread in the present time for their applications and safety aspects. ${ }^{2}$ Phospholipids primarily based DDS are found promising for higher and effective delivery of medication and providing abundant appropriate systematic drug delivery. In recent years, a variety of phospholipidrelated formulations, like Doxil ${ }^{3}$, Cleviprex ${ }^{4}$, Valium 5 and Silybin Phytosome ${ }^{\mathrm{TM}}$ 6, are employed in clinic, and achieving smart result. Various phospholipids, like soybean phosphatidylcholine, egg phosphatidylcholine, or artificial phosphatidylcholine, likewise as hydrogenated phosphatidylcholine, are normally utilized in differing kinds of formulations. Phospholipids become intriguing as they can offer numerous choices. However, the species diversity of lipoids varied how to select an appropriate phospholipid to achieve the therapeutic purpose become a vital drawback within the design of DDS, so we tend to summarized the structures, main sources, properties of phospholipids which might provide a guideline in the design of DDS. ${ }^{2}$

Phyto-phospholipid complex results from reaction of stochiometric quantity of lipoid (mainly Phosphatidyl choline) with extract or polyphenolic constituents like simple flavonoid in an aprotic solvent. The hypothesis of an interaction of flavonoids, terpenoids with phospholipids that which omnipresent in plants and animal, originated from the histochemical finding indicating that anthocyanosides from genus Vaccinium myrtillus L. show strong affinity for specific cellular structure rich in phospholipids. ${ }^{6}$ This review focuses on phospholipids that have been proven as excellent carriers for enhancing the solubility, bioavailability of herbal active components and their applications.

\section{CONSTITUENTS OF PHYTOSOMES}

\section{Phospholipids}

Phospholipids are molecules in which a hydrophilic head (polar) a group, and hydrophobic (Non-polar) acyl chains are coupled to the alcohol. The difference in polar groups, aliphatic chains and alcohols lead to the existence of a large variety of lipids. Phospholipids are lipids containing phosphorus, a polar potion and non-polar potion in their structures. ${ }^{2}$ Phospholipids offer the potential to improve the bioavailability of herbal medicinal active ingredients while minimizing changes in plasma profile data, but characterization of appropriate lipid excipients for the needs of the body is a prerequisite. Drug Delivery Systems Depending on Intended Use Commercial covers all major issues such as technology transfer and manufacturing issues from laboratory scale to commercial scale. ${ }^{7}$ All biological membranes consist of a mixture of different classes of phospholipids, Phospholipids can be divided into glycerophospholipids and sphingomyelins depending on the backbone $^{8}$. Additionally such as phosphatidylcholine (PC), phosphatidylethanolamine (PE), phosphatidylinositol (PI), phosphatidic acid (PA), and phosphatidylserine (PS). ${ }^{7}$ Phosphatidylcholine (PC), Phosphatidylethanolamine (PE), and phosphatidylserine (PS) are the main phospholipids used to prepare complexes that are composed of a hydrophilic head group and two hydrophobic hydrocarbon chains. $^{9}$ Among these phospholipids, Phosphatidylcholine is the used to accustomed prepare lipids complexes. The benefits of Phosphatidylcholine include their amphipathic property that provides it moderate solubility in water and lipid media. Moreover, PC is a vital element of cell membranes, and consequently it exhibits robust biocompatibility and low toxicity. Phosphatidylcholine molecules exhibit hepatoprotective activities, and have been reported to show clinical effects in the treatment of liver diseases, like liver disease, hepatitis, and hepatocirrhosis. Patel et al. prepared high-affinity tiny molecule phospholipid complexes of siramesine and Phosphatidic acid (PA). ${ }^{8}$

\subsection{Structures of Phospholipids}

Phospholipids containing glycerol's are called glycerol phospholipids, according to the alcohols contained in the phospholipids, they can be divided into glycerol phospholipids and sphingomyelins.

\subsubsection{Glycerophospholipids:}

Glycerophospholipids, typically referred to as phospholipids, are present in nature and are key elements of the lipid bilayer of cells. ${ }^{10}$ Glycerophospholipids which are the most phospholipids in eukaryotic cells, refer to the phospholipids during which glycerine is that the backbone. All naturally occurring glycerophospholipids possess L-configuration and a-structure. ${ }^{11}$ Glycerophospholipids (GPLs) are fatty acid diglycerides with a phosphatidyl organic compound connected to the terminal carbon. The terminal ester groups (X) are in the main ethanolamine, choline, serine, or inositol. GPLs are extremely amphiphilic and usually are elements of cellular or vesicle membranes. The commercial term phospholipid is widely used for GPL mixtures, that contain largely phosphatidyl vitamin B. Lecithin's are employed in foods as emulsifiers and surface-active agents for altering viscosity and crystallization properties. ${ }^{12}$

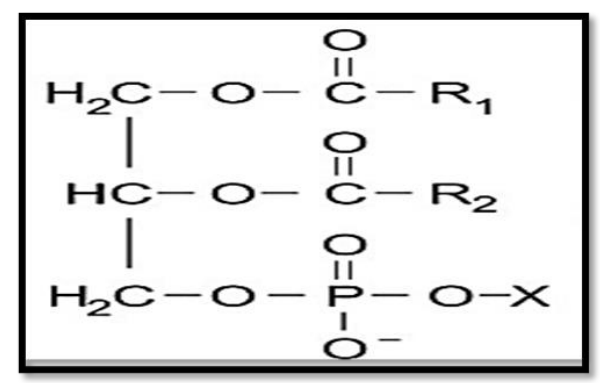

Figure 1: Structure of phospholipids. ${ }^{12}$

Variation in the head group leads to different glycerophospholipids, such as phosphatidylcholine (PC), phosphatidylethanolamine (PE), phosphatidylserine (PS), phosphatidic acid (PA), phosphatidylinositol (PI), phosphatidylglycerol (PG) cardiolipin (CL). The length of the polar moieties leads to different glycerophospholipids, e.g., dipalmitoyl, dimyristoyl, distearoyl PC. The saturation of aliphatic groups characterizes different glycerol- 
phospholipids, such as dioleoyl, distearoyl PC. The type of bonding (ester or ether) between aliphatic chains and glycerol determines different glycerophospholipids, such as plasmalogen. ${ }^{9}$

\subsubsection{Sphingomyelins}

In 1884, Thudicum was isolated from brain tissue and give name sphingomyelin (SM), structure of this sphingophospholipid was reported in 1927 to be N-acylsphingosine-1-phosphorylcholine. Sphingomyelins (SM) are a vital component of animal cell membranes. Although phosphatidylcholine and Sphingomyelins are similar in molecular structure, they still have some differences. 1) Each Sphingomyelins molecule averagely contains $0.1 \mathrm{e} 0.35$ cisdouble bonds in amide-linked acyl chains, and phosphatidylcholine contains 1.1e1.5 cis-double bonds. 2) The backbone of SM is a sphingosine, while the backbone of PC is a glycerol.2 The typical acyl lengths of the naturally occurring sphingomyelins are usually more than 20 , while the paraffin residues of sphingosine are relatively shorter, so the SMs are have a asymmetric molecules. ${ }^{13}$

Sphingomyelins are capable of forming intermolecular and intramolecular hydrogen bonds; therefore, the SM and PC bilayer have a significant difference within the macroscopic properties. The range of phase transition temperature of all naturally occurring is 30 to $450 \mathrm{C}$ that is above the natural phosphatidylcholines. numerous observations have shown that sphingomyelins and cholesterol have a very fundamental interaction. the reason for this phenomenon is that higher saturation of the acyl group chain of sphingomyelins results in stronger interaction with steroid nucleus.

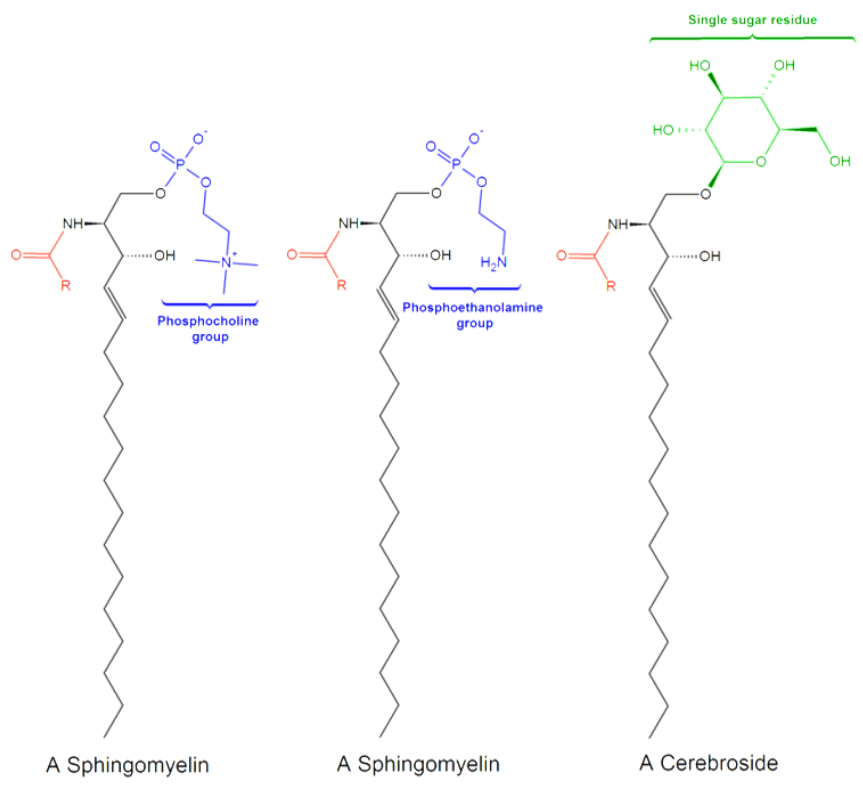

Figure 2: Various structure of Sphingomyelin. ${ }^{13}$

Sphingomyelin (SM) undergoes significant interactions with cholesterol. cholesterol has the flexibility to eliminate the liquid to solid phase transition in phospholipids. because of sphingomyelin transition temperature being among physiological temperature ranges, sterol will play a major role within the part of sphingomyelin. Sphingomyelin are additional prone to intermolecular hydrogen bonding than different phospholipids. Sphingomyelin (SM) is synthesized at the endoplasmic reticulum (ER), wherever it can be found in low amounts, and at the trans Golgi. it's enriched at the plasma membrane with a larger concentration on the outer than the inner leaflet.14 The Golgi complex represents plasma membrane intermediate between the ER and semipermeable membrane, with kind of higher concentrations towards the side. ${ }^{15}$

\subsection{The key Phospholipid Sources:}

According to the sources state that phospholipids can be divided into 1) Natural phospholipids and 2) Synthetic phospholipids.

\subsubsection{Natural Sours of Phospholipids.}

Natural phospholipids may be obtained from vegetable sources such as, for example, soya beans, canola seed, wheat germ, sunflower and flaxseed, and animal material such as egg yolk, milk or krill. These raw materials are produced on a very large-scale of countries. Worldwide soya bean harvest in 2013 amounted to 280 million tons and annual world production of soya bean oil amounted to about 42 million tons. ${ }^{16}$ Fourcroy was likely to be the first to find evidence of complicated aliphatic compounds in 1793. Uauquelin discovered phospholipids in human brains in 1812. In 1846, phospholipids were isolated from egg yolk by Gobley.separated phospholipids from egg yolk. The term "lecithin" that is derived from the Greek lekithos was used to aliphatic describe a sticky orange material isolated from egg yolk. when after years, B vitamin component in phospholipid was determined. ${ }^{17}$ Currently, three definitions of "lecithin" appear in the literature, which include: 1) from a business perspective, "lecithin" involves primarily Phosphatidylcholine, PE, PS, PI, other phospholipids, triglycerides, fatty acids and carbohydrates; 2) from a historical perspective, "lecithin" refers to phosphorous lipids segregated from eggs and brains; 3 ) from a scientific point of view, "lecithin" refers to PCs.[18] The cost of phospholipids separated from natural sources is always lesser than that of synthetic or semi-synthetic methods. For natural phospholipids, the higher purity they are, the higher the price. (2) Phospholipids isolated from plants and animals Purified to multiple stages, including pharmaceutical and food grades.

\subsubsection{Soybean Lecithin}

The raw soybean lecithin obtained is being used as the starting material for the production of large-scale lecithin soybean fractions with a larger PC content. Good yield is obtained by extraction methods using non-toxic acetone and biofuel solvents, followed by chromatographic purification procedures and appropriate solvent removal methods. All solvents can be recovered and recycled. By selecting the appropriate successive extraction and chromatography methods, several lecithin fractions between PC content (20$80 \%$ ) and PC purity (98\%) and the ratio of phospholipids to non-polar lipids can be reproducibly achieved. For soybean oil and all vegetable oils used to manufacture lecithin/PC, this method applies. The different phospholipids that are present in soybean lecithin, N-acyl-PE.PA, PE, PC, PI, and Lyso-PC(LPC) are separated at increasing retention time. 


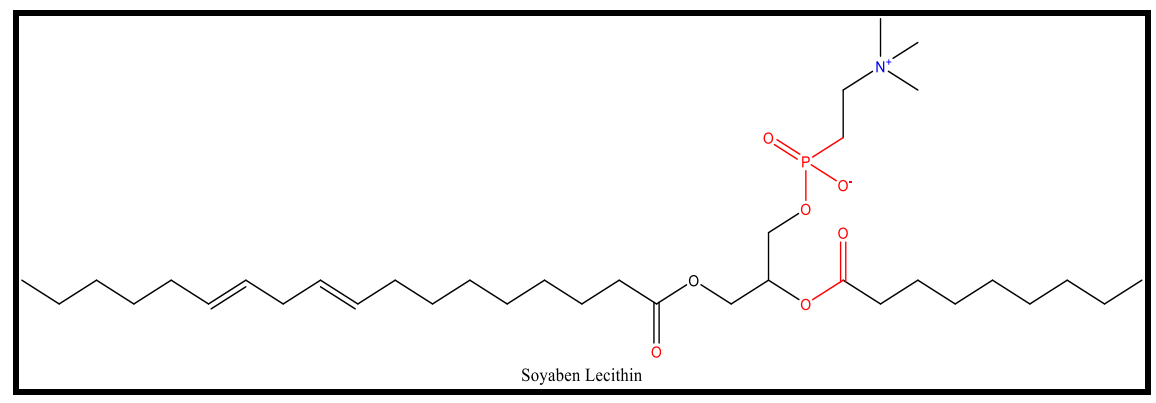

Figure 3: Structure of Soyabean Lecithin.

As derived from these High - performance liquid chromatography chromatograms and additional TLC studies (not shown), the more detailed lipid profile shows, depending on the number of extraction and chromatography steps, an increase of the PC content to $98 \%$ and, simultaneously, a decrease of the other lipid.

\subsubsection{Egg Lecithin}

The French chemist and pharmacist Theodore Gobley first isolated egg lecithin in 1846.[1] Gobley originally isolated lecithin from egg yolk (lekythos) in ancient Greek is 'egg yolk' and in 1874 established the complete chemical formula of phosphatidylcholine. ${ }^{18}$ Egg phospholipids are separated from egg yolk with same extraction and chromatography techniques to soya phospholipid. ELSD-equipped lipoid profiles of egg phospholipid extraction/chromatography fractions as measured with HPLC indicate the presence of computer, PE, SM, LPE, and LPC within the fractions with 6479 phosphatidylcholine, while the phosphatidylcholine content increases up to $98 \%$ and therefore the other lipids are removed with exception of a small quantity of SM. Egg lecithin is typically extracted chemically using an ethanol, acetone, petroleum ether but not benzene or hexane because the pharmaceutical regulations limit residual solvents. ${ }^{19}$ It is an emulsifier, particularly for a parenteral uses because it does not needing to be metabolized. Its phospholipids can form either liposomes, bilayer sheets, micelles, or lamellar structures in an aqueous solution, depending on hydration and temperature.

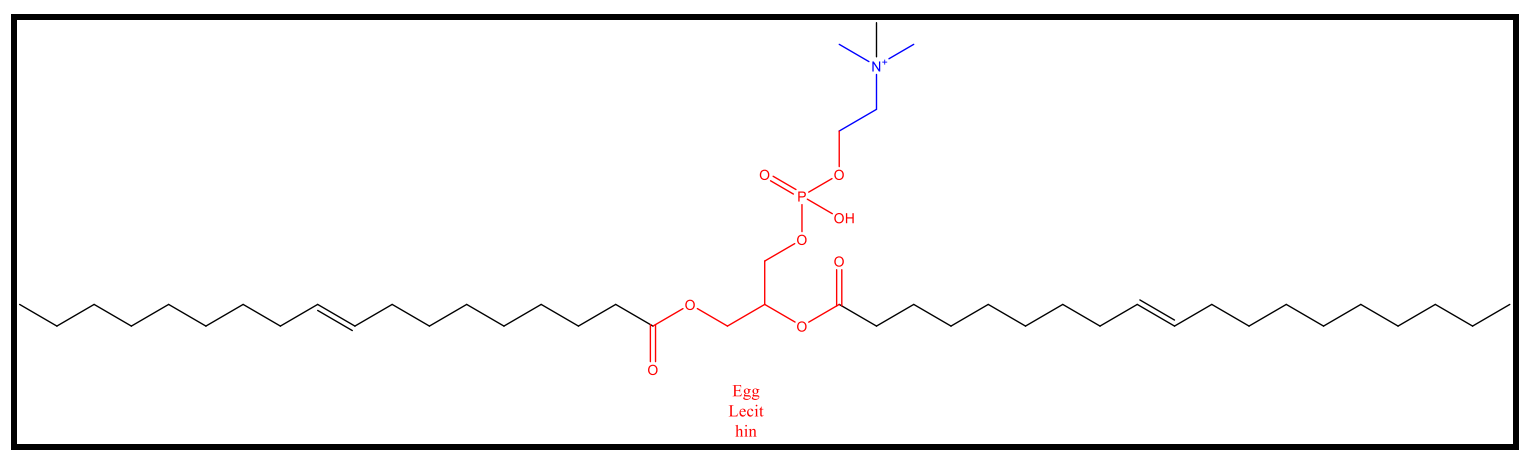

Figure 4: Structure of Egg Lecithin

They are palmitic acid (C16:0), stearic acid (C18:0), oleic acid (C18:1), linoleic acid (C18:2) and arachidonic acid (C20:4). For egg phospholipids, the presence of the polyunsaturated fatty acids $C$ 20:4 (n-6) and C22:6 (n-3) is common. There is a small difference between the various fractions in the ratio of the fatty acids. Considering the position of the fatty acid within the phospholipid molecule, egg PC comprises about 40\% 1-palmitoyl-2oleoylphosphatidylcholine.

\subsubsection{Hydrogenated Lecithin}

The result of regulated a hydrogenation (the addition of hydrogen) of lecithin is hydrogenated lecithin. In the formulation of numerous cosmetics, and personal care products, lecithin and hydrogenated lecithin are used. Saturated fatty acid with phospholipids possesses these properties and can be obtained by hydrogenation with unsaturated fatty acids of natural phospholipids. In this phase, in a catalytic reaction involving metal catalysts (e.g., nickel, palladium and platinum) bound to a porous carrier, the unsaturated fatty acids are saturated by hydrogen gas, usually in a heterogeneous system. ${ }^{20}$ Due to the presence of unsaturated fatty acids in natural phospholipids the liquid crystalline to gel phase transition temperature is below $0{ }^{\circ} \mathrm{C}$. These phospholipids are at ambient and body temperature in the liquid crystalline state and form upon hydration flexible structures/ menopause, suitable for specific pharmaceutical technological applications. In certain formulations, however, phospholipids with higher phase transition temperatures are preferred when, e.g., more mechanically stable liposomes with increased stability in blood plasma or when phospholipids with more powder-like properties are required. ${ }^{21}$

\subsection{Phyto-active Constituents.}

Medicinal plants are of great importance to the health of individuals and communities. The medicinal value of these plants lies in some chemical substances that produce a definite physiological action on the human body. Alkaloids, tannins, flavonoids, and phenolic compounds are the most significant of these bioactive constituents of plants. As spices and food plants, many of these indigenous medicinal plants are used. They are also often applied for medicinal purposes to foods meant for pregnant and nursing mothers. ${ }^{22}$ The chemical compounds of herbal extracts identified by researchers are generally identified on the basis of robust pharmacological in vitro rather than in vivo activity. ${ }^{22}$ The significant number of these compounds are polyphenols. Aegle marmelos, Cynodont dactylions, Eclipta prostrata, Moringa pterygosperma, Pongamia pinnata, Sida acuta and Tridax procumbens are widely used in herbal medicine in India. ${ }^{23}$ 
<smiles>COc1c(O)cc2oc(-c3ccc(O)c(O)c3)c(O)c(=O)c2c1O</smiles>

Patuletin<smiles>COc1ccc(-c2cc(=O)c3c(O)cc(O)cc3o2)cc1</smiles>

Acacetin<smiles>COc1cc(C(=O)[O-])cc(OC)c1O</smiles>

Syringic acid<smiles>O=c1cc(-c2ccc(O)c(O)c2)oc2cc(O)cc(O)c12</smiles>

Luteolin<smiles>C#CCN(C)C(C)Cc1ccccc1</smiles><smiles>O=C(O)/C=C/c1ccc(O)cc1</smiles><smiles>O=c1c(O)c(-c2ccc(O)cc2)oc2cc(O)cc(O)c12</smiles><smiles>O=C(O)CCc1cccc(O)c1</smiles><smiles>C#CCNC1CCc2ccccc21</smiles>

Rasagiline

Figure 5: Example of Some Phyto-active Constituents.

Some of the plants' biologically active polyphenolic constituents show affinity for the aqueous phase and, such as hesperidin, cannot transfer through biological membranes. Others, on the other hand, have high lipophilic properties and cannot dissolve in aqueous gastrointestinal fluids, such as curcumin and rutin. Phyto-phospholipid complexes cannot only increase the solubility of lipophilic polyphenols in aqueous environment, but also the membrane penetrability of aqueous phase hydrophilic complexes. In addition, polyphenols can protect the development of complexes from destruction by external forces, such as hydrolysis, photolysis, and oxidation. ${ }^{24}$

Other herbal extract molecules may also be prepared in complexes with phospholipids, such as 20(R)-25-methoxyldammarane-3 $\beta, 12 \beta, 20$-triol (25-OCH3-PPD) ${ }^{25}$, evodiamine (EVO), and siramesine (SRM) 26. Therefore, phytophospholipid complexes are no longer restricted to polyphenols, and the technique of producing complexes is technically sufficient for any active complexes. Flavonoids are classified as flavonoids (i.e., rutin and quercetin), flavones (i.e., luteolin [Lut]), flavonoids (i.e., catechin), isoflavones (i.e., daidzein and genistein), flavonoids (i.e., naringin and hesperetin), proanthocyanins and anthocyanins (i.e., cyaniding and pelargonidin). In the parent fruit and in our diet, they have several beneficial functions. ${ }^{27}$ The secondary plant metabolites that have impressive antioxidant, antimicrobial, and chelating properties belong to flavonoids. They could, have a lot of beneficial effects in food and health. There are several studies that indicate that these compounds have a protective function. has antioxidant properties and could have special cardioprotective effects. ${ }^{28}$

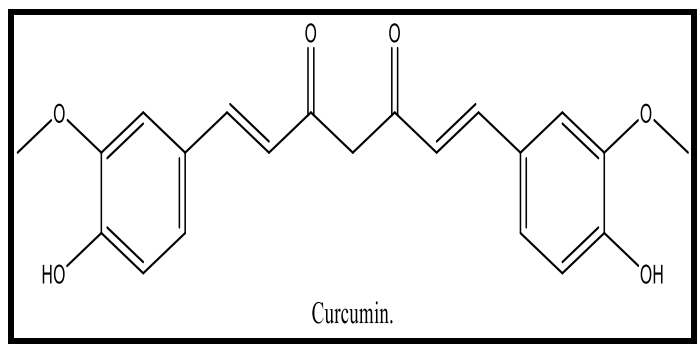

Figure 6: Structure of polyphenols curcumin.

\section{Solvent System for Phytosome.}

In phospholipid complexation technique the selection of solvent depends on the solubility of both drug and phospholipids. generally, polar aprotic solvents are typically used in phytosome preparation to provide a suitable environment supporting hydrogen bond formation. ${ }^{29}$ Various solvents have been used by different researchers as a reaction medium for the formulation of Phyto phospholipid complexes. Traditionally, aprotic solvents, such as aromatic hydrocarbons, halogen derivatives, methylene chloride, ethyl acetate, cyclic ethers, etc., have been used for the preparation of Phyto phospholipid complexes but have been largely replaced by protic solvents such as ethanol. ${ }^{30-31}$ Indeed, more recently, protonic solvents, such as ethanol and methanol, have been successfully used for the preparation of phospholipid complexes. For example, Xiao formulated silybinphospholipid complexes utilizing ethanol as a proton solvent; the proton solvent was subsequently removed under vacuum at $40^{\circ} \mathrm{C}$. Several kinds of solvents have been effectively studied. When the yield of phospholipid complexes is sufficiently large, ethanol can be a popular and effective solvent that leaves less residual residue and tends to cause minimal damage. In the presence of water or buffer solution, some liposomal drug complexes work where the phytosome interacts with a solvent with a reduced dielectric constant. $^{32}$

Recently, many studies have recently used the method of supercritical fluid to regulate the size, shape, and morphology of the material of interest. The supercritical anti-solvent process (SAS) is one of the SCF technologies that is becoming a promising technique for the development of controlled size and size distribution of Micronics and submicronic particles. ${ }^{33}$ A supercritical fluid (usually CO2) will be selected as an anti-solvent in this technique to reduce the solubility of the solution in the solvent. 
Table 1: Examples of Some Solvent used in Preparation of Phytosomes.

\begin{tabular}{|l|l|l|l|}
\hline Sr.no. & Solvent & $\begin{array}{l}\text { Boiling } \\
\text { Point 0C }\end{array}$ & $\begin{array}{l}\text { Melting } \\
\text { Point 0C }\end{array}$ \\
\hline 1 & Ethanol & 78.5 & -117 \\
\hline 2 & Chloroform & 62 & -63 \\
\hline 3 & Tetrahydrofuran & 65 & -108 \\
\hline 4 & DMSO & 190 & 19 \\
\hline
\end{tabular}

\section{Chemical Interaction between Phytoconstituents and Phospholipid}

Plant constituents or herbal extracts especially polyphenolic compounds form complexes with phospholipid molecules through the formation of chemical bonds between photoactive molecules and phospholipids. This can be demonstrated or established by the thermal analysis of Phyto phospholipid complexes in relation to the pure drug and Phyto phospholipid mixture. 34 A chemical bond between a flavonoid molecule and a phospholipid molecule was reported by Bombardelli in $1989 .{ }^{35}$ Controversies have arisen in the past concerning the formation of Phyto phospholipid complexes. ${ }^{36-37}$ Eventually, the drug phospholipid complexes (aptly referred to as phytosomes) gradually attracted people's attention and their studies are increasing. Subsequent researchers found that phospholipid complexes can be made of many types of natural ingredients and natural extracts. The interaction between the two molecules was due to the formation of hydrogen bonds and/or hydrophobic interactions. ${ }^{37} \mathrm{~A}$ research on the molecular level interaction of the 20(S)protopanaxadiol phospholipid complexes using molecular docking showed that a hydrogen bond was formed between one of the 20(S)-protopanaxadiol-OH group and the phospholipids- $\mathrm{P}=0$ group. ${ }^{38}$ The spectroscopic data indicate that the phospholipid-photoactive ingredient interaction is due to the formation of hydrogen bond between the polar head and the polar functionalities of the active ingredient are revealed by phyto-phospholipid complexes employed by reaction of stoichiometric phospholipid quantity and the phytoconstituents complex. ${ }^{39}$ It is also possible to draw the same conclusion from the In other studies, thermal analysis shows that the interaction between the two molecules had been attributed to formation of hydrogen bond or hydrophobic interaction. ${ }^{40}$

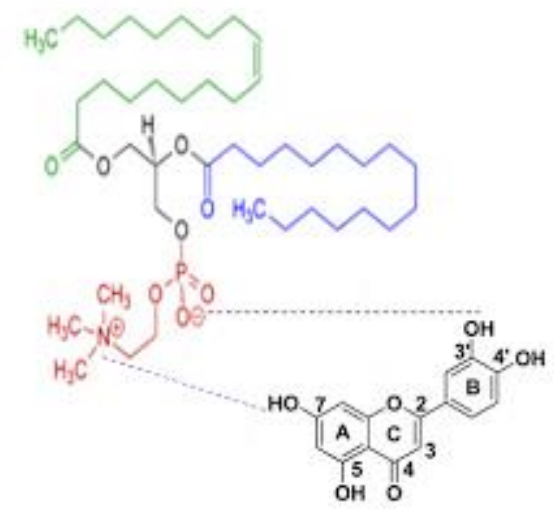

Figure 7: Interaction between Photoactive constituent and phosphatidylcholine. ${ }^{7}$

The PC consists of two major parts, namely the phosphatidyl moiety (lipophilic) and the choline moiety (hydrophilic).
Choline binds to the respective active compounds/extracts and the portion of phosphatidyl encloses the choline-bound structure as an envelope. ${ }^{30,41}$ The shape and integrity of the Phyto phospholipid plant active component complex contributes to easy diffusion across the cell barrier because phosphatidyl choline is a major molecular building block of the cell membrane and is easily solubilized in water; in addition, the oil/lipid environment acts as convoy for phytoconstituents that allows them to pass through biological membranes. ${ }^{42}$

\section{Stoichiometric ratio of Phyto-active constituents and phospholipid}

In general, 1:1 molar ratio test batch of phytosome complex of plant extract and phospholipid were prepared using various methods. Phyto phospholipid complexes are used to react synthetic or natural phospholipid with active constituents in a molar ratio of 0.5 to $2.0 .^{39}$ For example, Quercetin-phospholipid complexes were prepared by mixing Lipoid S 100 and Quercetin at a 1:1 molar ratio. ${ }^{43}$ Different stoichiometric ratios of active components and phospholipids were used, however. Yue et al. performed a comparative analysis to produce oxymatrine-phospholipid complexes using the stoichiometric ratios of $1: 1,1.4: 1,2: 1$, 2.6:1, and 3:1; Determined that the optimum quantity was obtained at a ratio of 3:1.44 Therefore, for the formulation of phospholipid complexes, a stoichiometric ratio of 1:1 is not always appropriate. We can experimentally modify the stoichiometric ratio of bioactive constituents and phospholipids for various types of drugs according to separate uses, such as the highest drug loading.

\section{Structure of Phytosome}

The phytosome contains two terms: a phyto and some. Phyto refers to the bioactive portion of the phytosome complex originating from plants. Some represent the complex's a final structure with a similarity to the membranes of the cell membranes. Compatibility with lipophilic and hydrophilic mediums has been demonstrated by phytosome complexes. In the case of chemical structures, they are similar to cell membranes and are known as a mechanism of phyto-lipid delivery. ${ }^{45}$. Nonpolar solvents, which are used for production of the phytosomes, provide proper interactions between phospholipids and polyphenols. ${ }^{46}$ Phytosome formation is based on hydrogen bonds (H-bonds), the main interaction between the polar parts of the phospholipids (i.e., phosphate groups) and the bioactive material that occurs in phytosomal structures. In this case, it was reported that the main interaction occurring in catechin-loaded phytosomes was the formation of H-bonds between the phosphate group of phosphatidylcholines and the hydroxyl portion of the catechin. ${ }^{47}$ In general, the structure of phytosomes is similar to liposomes when exposed to water. The mixing of bioactive ingredients with PC in specific ratios is a major step in the production of phytosomes and liposomes. ${ }^{48}$

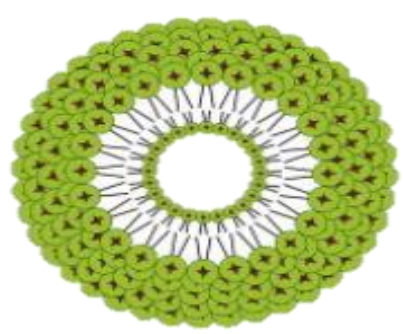

Figure 8: Structure of phytosome. 
PC, the main molecule present in cell membranes, is miscible with both lipophilic and aqueous media. Therefore, the main reason for using PC in the phytosomal structure is making the phytosome mimic the cell membrane, causing rapid and easy absorption. ${ }^{49}$

\section{Methods of Preparation Phyto- phospholipid Complex.}

A phytosome is prepared by complexing a polyphenolic phytoconstituent or a mixture of phospholipids. Mass ratios in 1:1.5-1:4 is observed, depending on the product. 50 Various methods of preparation for the phytosome and the resulting complex may vary depending on the protocol used. There are three primary methods for preparation of Phyto phospholipid complexes, including anti-solvent precipitation, solvent evaporation, freeze-drying.

\subsection{Antisolvent Precipitation Technique.}

Mukherjee et al. have patented a similar method for the preparation of andrographolide phytophospholipid complexes using dichloromethane as a reaction medium and n-hexane as an anti-solvent for the final precipitation of the product. ${ }^{51}$ Many researchers have also used the traditional anti-solvent precipitation technique by incorporating $n$ hexane as an anti-solvent to precipitate the drug phospholipids complex from an organic solvent. ${ }^{52}$ In a 100 $\mathrm{ml}$ round bottom flask, a specific amount of herbal extract and soy lecithin was taken and refluxed with $20 \mathrm{ml}$ of dichloromethane for $2 \mathrm{~h}$ at a temperature not exceeding $60 \mathrm{oC}$. The mixture is concentrated in $5-10 \mathrm{ml}$. Hexane $(20$ $\mathrm{ml}$ ) was carefully added with continuous stirring to obtain the precipitate that was filtered and collected and stored overnight in vacuum desiccators. ${ }^{53}$ Research work is based on a patented similar method for the preparation of the andrographolide phyto-phospholipid complex using dichloromethane as the reaction medium and n-hexane as the final precipitation anti-solvent of the product. The solution is then evaporated and the residue is usually dried Vacuum-based. ${ }^{51}$

\subsection{Solvent Evaporation Technique.}

In the most frequently used solvent evaporation technique, the drug and phospholipids are placed in the same flask containing an appropriate solvent system, such as tetrahydrofuran or ethanol. The reaction shall be carried out at an appropriate fixed temperature for a fixed duration of time in order to obtain the maximum possible yield and trapping of drugs. Sikarwar et al. formulated marsupsinphospholipid complex by means of a mechanical dispersionoriented liquid anti-solvent precipitation process, ${ }^{54}$ They dissolved soy lecithin in diethyl ether by sonication and marsupsin in double distilled water. The drug solution was then added drop wise to the phospholipid solution with sonication. The resultant formulation was then refrigerated and on analysing the complex showed $44 \%$ entrapment of marsupsin with $20 \%$ cumulative drug release.

\subsection{Rotary Evaporation Technique.}

The complex of plant extracts or specific active principles with dietary phospholipids is generally prepared by solvent evaporation techniques using alcoholic or organic solvents as reaction medium. In the more frequently used solvent evaporation technique the drug and the phospholipids are placed in the same flask containing a suitable solvent system such as tetrahydrofuran or ethanol. The specific amount of plant extract and soya lecithin was dissolved in THF in a rotary RBF followed by stirring for $3 \mathrm{~h}$ at a temperature not exceeding $40 \mathrm{oC}$. Thin film of the sample was obtained to which n-hexane was added and continuously stirred using a magnetic stirrer. The precipitate obtained was collected, placed in amber coloured glass bottle and stored in refrigerator. The reaction is allowed to be carried out at suitable fixed temperature for a fixed duration of time to get maximum possible yield and drug entrapment.

\subsection{Super Critical Fluids (SCF).}

Super critical fluids (SCFs) have emerged as an effective tool for the preparation of particles of a size ranging from 5 to $2000 \mathrm{~nm}$. Various methods of supercritical fluid have been used to improve the solubility profiles of poorly soluble drug candidates, some of which are compressed anti-solvent process (PCA), supercritical anti-solvent method (SAS), rapid expansion of supercritical solutions (RESS), gas antisolvent technique (GAS) and solution enhanced dispersion by supercritical fluids (SEDS). Li et al. have incorporated a supercritical fluid technique for the preparation of the purarin-phospholipid complex.55-56 The complex was formulated using three different conventional methods. Solvent evaporation, lyophilization and micronized purarin compared qualitatively with the complex prepared by the supercritical anti-solvent precipitation technique.

Two SCF techniques. GAS and SEDS have been used for the preparation of complexes. In the GAS technique, a supercritical antisolvent was added to the drug and phospholipid solutions separately until the final pressure was reached. The reaction vessel was then kept at a fixed temperature of $38{ }^{\circ} \mathrm{C}$ at a pressure of $10 \mathrm{mPa}$ for $3 \mathrm{~h}$ without any agitation. In the SEDS technique, the liquid solution and the supercritical anti-solvent were continuously added to the precipitation unit. Carbon dioxide gas was allowed to pass through a $0.1 \mathrm{~mm}$ diameter nozzle into a mixture of phospholipids and purarin in the solvent. The experimental conditions were optimized with a temperature of $35^{\circ} \mathrm{C}$, a pressure of $10 \mathrm{mPa}$, a drug-to-phospholipid mass ratio of $1 \%$ and a purarin concentration of $100 \mathrm{mg} / \mathrm{ml}$. The resulting method produced a 93\% yield complex. The morphology of the product obtained from the SEDS technique was found to be in the form of aggregated particles with an ordered appearance of approximately $1 \mu \mathrm{m}$ in size, while those formed by conventional methods were in the form of nubby granules with fused or viscous plates. The surface area of the particles formed by SEDS increased from 0.50 to 1.08 . The supercritical complex of phospholipids exhibited rapid dissolution with an increase of 1,91-fold from $2,87 \mathrm{mg} / \mathrm{ml}$ of purarin to $5,49 \mathrm{mg} / \mathrm{ml}$ of its phospholipid complex. The product of the supercritical GAS technique has been shown to have more precisely controlled morphological characteristics, while the particles of the SEDS technique have represented a complete loss of crystallinity.

\section{Factors of Influence of Phytophospholipid Complexes}

Factors that influence the formation of phytophospholipid complexes include mainly solvent, stoichiometric ratio of active ingredients, reaction temperature and reaction time. ${ }^{57-60}$ Different process variables may be selected based on the desired goal. For maximum yield, Saoji et al. studied the influence of process variables such as phospholipid-todrug ratio, reaction temperature and reaction time, and used the central composite design to obtain the optimal formulation. ${ }^{57}$ According to a recent report, ${ }^{61}$ Telange and his colleagues prepared the highest-yield apigeninphospholipid complexes by adjusting stoichiometric ratios and reaction temperature. 


\section{Advantages of Phytosomes}

\subsection{Hepatoprotective Effect Phytosome.}

Compared to carriers employed in other drug delivery systems, phosphatidylcholine is a crude ingredient that also has significant therapeutic benefits. ${ }^{33}$ Phosphatidylcholine not only acts as an ingredient added to the formulation of phytophospholipid complexes, but also acts as a hepatoprotective agent. So, when the patient is taking phosphatidylcholine, the synergistic effect will be shown to protect the liver. In certain situations, phospholipids also have nutritional benefits. Most phytosome studies focus on Silybum marianum Gaertner and its liver-protective flavolignans. Flavonoids exhibiting hepatoprotective properties are found in the fruit of milk thistle (Silybum marianum). ${ }^{62-63}$ Silymarin has been shown to be effective in the treatment of various diseases of the liver, including hepatitis, cirrhosis, fatty infiltration of the liver (chemical and alcohol-induced fatty liver) and inflammation of the bile duct. 64-66. Since 1994, Choline has been reported that it is necessary for norm al liver function. ${ }^{67}$ In vitro studies have shown that these PLs increase hepatic collagenase activity and may thus help prevent fibrosis and cirrhosis by encouraging collagen breakdown. ${ }^{68}$

In addition, lecithin has been verified to have a protective effect on non-alcoholic fatty liver disorders as well as protection against various other toxic substances such as hepatitis $\mathrm{A}$ and $\mathrm{B}^{69}$. As a result, it has a great protective effect on liver function. Khan et al. prepared a luteolin phospholipid complex (LPC) by solvent evaporation and its hepatoprotective potential against D-galactosamine and hepatic-induced lipopolysaccharide (GalN/LPS) was assessed. ${ }^{70}$ Silymarin's antioxidant properties significantly improve the resistance of the liver to toxic insults. Silymarin has a complex composition, based on three patterns of covalent interaction between its flavanols and lignan components. Silybin, in turn, a mixture of two diastereomers, is the major and more potent component of silymarin. ${ }^{62}$ Silybin protects the liver by conserving glutathione in parenchymal cells. ${ }^{71}$ while phosphatidylcholine helps to repair and replace cell membranes. ${ }^{72}$ These constituents act synergistically, saving liver cells from destruction. Although silybin was found to be active in many models of human disease, it's extremely poor oral bioavailability hindered the clinical translation of these results. The oral bioavailability of silybin in a pharmacokinetic study. ${ }^{73}$ Remarkably increased when administered as a silybin-phospholipid complex. The increased lipophilicity of the silybin-phospholipid complex was claimed to explain improved bioavailability. ${ }^{72}$

\subsection{Enhance Percutaneous Absorption.}

Phytophospholipid complexes can easily move from the hydrophilic environment to the lipophilic environment of the cell membrane and enter the cell. ${ }^{74} \mathrm{~A}$ large number of studies have therefore shown that the percutaneous absorption of phytoconstituents is enhanced by the application of phytoconstituents in the form of phytosomes. In the transdermal region, phytophospholipid complexes are commonly used due to the above characteristics of skin penetration..$^{75}$ According to a recent study, a 2\% quercetinphospholipid cream was prepared by Stefano TOGNI et al. to improve the protection and tolerability of the quercetinbased formulation. ${ }^{76}$ In order to overcome the problem of lower skin penetration of Citrus auranticum and Glycyrrhiza glabra, Damle and Mallya developed a novel complex of phytophospholipid creams. ${ }^{77}$

\subsection{Cardiovascular properties of phytosomes.}

It has been shown in preliminary studies that the phytosome of G. Bilob L. And the extracts of grape seed are more potent than their uncomplicated forms. The efficacy of ginkgo selected phytosomes in the treatment of peripheral vascular disease (e.g., Raynaud's disease and intermittent claudication) was found to be 30-60 per cent higher than that of ginkgo selected. Ginkgoselet phytosome was also recently validated as a cardioprotective agent. ${ }^{78}$ The two of the G. L biloba. Different cognitive effects were demonstrated by PHYTOSOME® complexes, with the phosphatidylserine complex (Virtiva ${ }^{\circledR}$ ) active at lower doses than the normal phosphatidylcholine complex (Ginkgoselect PHYTOSOME). ${ }^{79-80}$ The activity of Leucoselect $\circledast$ PHYTOSOME® to reduce low-density lipoprotein susceptibility to oxidation and oxidative stress damage in a group of heavy smokers was also investigated, with positive results. 81

\subsection{Anti-aging properties of Phytosome.}

Phytosome as a delivery system offers interesting applications and opens new opportunities for the use of active ingredients in the cosmetic field. G. The G. Biloba PHYTOSOME has been investigated for the treatment of skin aging associated with superficial capillary blood flow. Extracts from G. biloba are used orally to improve peripheral circulation 81 , and their phospholipid complexes were found to improve skin microcirculation after topical application. Activation of microcirculation decreased skin aging associated with dystrophic epidermal and dermal modification and regressive abiotrophic pinnacular disease associated with venous stasis and/or persistent venous insufficiency of the lower limbs and breasts. The role of PHYTOSOME $®$ in functional cosmetics has been reviewed, 82 and the use of Silymarin PHYTOSOME ${ }^{\circledR}$ in aging skin has also been reported. $82-83$

\subsection{Enhance the Bioavailability.}

Greenselect phytosome contains a fully standardized polyphenol fraction (not less than 66.5 per cent) derived from green tea leaves, mainly characterized by the presence of epigallocatechin and its derivatives. These compounds are powerful modulators of various biochemical processes associated with homeostasis breakdown in major chronicdegenerative diseases such as cancer and atherosclerosis. ${ }^{84}$ Anthocyanosides obtained from the extracts of bilberry (Vaccinium myritillus), were complexed to make Mirtoselect phytosome. It improves capillary tone, reduces abnormal blood vessel permeability, and is potent antioxidants. Standardized extract from Melilotus officinalis, used for preparation of Lymphaselect phytosome is particularly indicated for venous disorders, including chronic venous insufficiency of the lower limbs, and treat insomnia.

Several studies have shown that phyto-phospholipid complexes can improve oral topical absorption, thereby increasing bioavailability and reducing the dose needed. It can, therefore, significantly enhance therapeutic benefits. Zhang et al. prepared 25-OCH3-PPD phospholipid complexes by solvent evaporation and found that the complex's AUC (0-24 h) increased from 26.65 to 97.24 , which was 3.65 -fold higher than free $25-0 \mathrm{CH} 3-\mathrm{PPD}$, resulting in a $365 \%$ relative bioavailability. 85 Zhang prepared the phospholipid complexes of quercetin and showed that the quercetinphospholipid complex AUC(0-t) increased from 2.04 to 8.12, a 3.98-fold increase. ${ }^{85}$ Chen et al. investigated the pharmacokinetic profile and oral bioavailability of these complexes by comparing antioxidants, kaempferol and isorhamnetin extracts from Ginkgo biloba (GBE) to their 
respective phosphatidylcholine complexes (GBP) in rats. AUC0-T increased by 2.42, 1.95, and 2.35-fold for quercetin, kaempferol, and isorhamnetin for GBP. This indicated that bioavailability was significantly enhanced by GBP compared with GBE. ${ }^{86}$ After the formation of phytophospholipid complexes, the permeability of the membrane and the oilwater partition coefficients of the active constituents have significantly improved. Phytophospholipid complexes are therefore more easily absorbed and generate higher bioavailability compared to free active ingredients. As a result, the preparation of phytophospholipid complexes has recently received increased attention. Phytosomal formulations have also gained important applications in the pharmaceutical industry. In addition, products based on phyto-phospholipid complexes, such as Silymarin Phytosome $\AA$ from milk thistle seed for antihepatotoxic activities, ${ }^{87}$ have been made available on the market to treat many diseases or improve human health.

\section{Characterization of Phytosomes Complexes.}

The physical attributes such as shape, size, distribution, drug entrapment capacity, drug release and chemical composition are used for their characterization. Methods used for their characterization are Infra-Red Spectroscopy, NMR Spectroscopy, Differential Scan Calorimetry, Transmission Electron Microscopy (TEM), Photon correlation Spectroscopy (PCS), (NMR) Nuclear Magnetic Resonance, Percentage drug entrapment, Solubility study. etc. ${ }^{88}$

\subsection{Particle Size and Zeta Potential.}

Particle size and zeta potential are important properties associated with stability and reproducibility of complexes. In general, the average particle size of phospholipid complexes ranged from $50 \mathrm{~nm}$ to $100 \mu \mathrm{m}$. Mazumdar prepared singing phytosome complexes and the mean particle size and zeta potential of the complex were $153 \pm 39 \mathrm{~nm}$ and 10,09 $\pm 0,98$ $\mathrm{mV}$, respectively. ${ }^{89}$ From a theoretical point of view, the zeta potential is the electrical potential of the interfacial double layer (DL) at the position of the slippery plane relative to the point of the bulk fluid away from the interface. ${ }^{90-91}$ The potential difference between the dispersion medium and the stationary layer of fluid attached to the dispersed particle is zeta potential, in other words.

\subsection{Scanning Electron Microscopy (SEM).}

The Scanning Electron Microscopy (SEM) provides a photomicrograph of the phytosome with an appropriate magnification after coating with gold. Surface morphology studies are often important for the identification of trapping behaviour, surface properties, and the presence or absence of impurities on the surface. Generally, the surface of phytosomes shows no crystalline particles or impurities on the surface. The spherical bulging on the surface is generally obtained, confirming the spherical shape of the phytosomes. ${ }^{39}$ SEM has provided important insights into the properties of the solid state and the surface morphology of the complex. SEM has shown that active compounds can be visualized in a highly crystalline state, but the shaped crystals disappear after the complexion. TEM showed that phytophospholipid complexes exhibit vesicular-like structures when diluted in distilled water under slight shaking. ${ }^{89}$ Udapurkar PP et, al,. are developed Phytosomes: development, optimization and physicochemical characterization. DN and DN-PC were coated with gold in a Fine Coat Ion Sputter S-4800 TYPE II, Hitachi high technologies corporation, Japan. Analysis was done on the coated sample by placing a pinch of sample in the S-4800 TYPE II (Hitachi high technologies corporation, Japan)
Scanning electron microscope and surface morphology was viewed and photographed. ${ }^{92}$

\subsection{Transmission Electron Microscopy (TEM).}

The transmission electron microscope is a powerful tool for material science. The high energy beam of electrons shines through a very thin sample, and interactions between electrons and atoms can be used to observe features such as the crystal structure and features of the structure, such as dislocations and grain boundary. Chemical analysis may also be carried out. The growth of layers, their structure and defects in semiconductors can be studied using TEM. High resolution may be used to analyse the quality, shape, size and density of quantum wells, wires and dots. ${ }^{93}$

\subsection{Differential scanning calorimetry (DSC).}

The most popular thermal analysis technique, the' workhorse' of thermal analysis, is differential scanning calorimetry (DSC). This is a relatively new technique; its name has existed since 1963, when Perkin-Elmer commercialized its DSC-1, the first DSC. The DSC term simply means that quantitative calorimetric information can be obtained on the sample during a linear temperature ramp. DSC is a technique according to the ASTM standard E473 in which the difference in heat flow rate into a material is determined by comparison as a function of temperature while the sample is subjected to a regulated temperature program. The simple and quick determination of the glass transition temperature, the heat ability jumps at the glass transition, melting and crystallization temperatures, fusion heat, reaction heat, very fast determination of purity, rapid measurements of heat capacity, thermoset characterization, and measurements of liquid crystal transitions must be listed among the DSC applications. ${ }^{94}$

Interactions can be observed in DSC by comparing the temperature of transition, the appearance of new peaks, the absence of original peaks, melting points, and changes in the region of relative peaks. ${ }^{75}$ In contrast to those of a physical mixture, phyto-phospholipid complexes typically exhibit radically different characteristic peaks. It is believed that strong interactions occur in the active ingredients in addition to the two fatty chains of phospholipids and free rotation is also inhibited by the polar portion of phospholipids. Das and Kalita prepared rutin-containing phyto-phospholipid complexes and the resulting DSC thermogram showed two characteristic peaks lower than those of the physical mixture and rut peaks. ${ }^{60}$ Udapurkar PP et, al,. are prepared phytosomes the resulting interactions are observed as the elimination of endothermic peak, the appearance of new peak, change in peak shape, onset temperature/melting point, relative peak area or enthalpy. ${ }^{95}$ The DN revealed wide endothermic peaks at $126,48^{\circ} \mathrm{C}$ and $272,79^{\circ} \mathrm{C}$. The DSC DN-PC thermogram showed that the complex yields two endothermic peaks at $206.40^{\circ} \mathrm{C}$ and $244.54^{\circ} \mathrm{C}$. As a result, it has been shown that the shift of the endothermic peak at a difference of around $25-30^{\circ} \mathrm{C}$ suggests possible interaction of DN with the PC and may account for enhanced entrapment. ${ }^{92}$

\section{5(NMR) Nuclear Magnetic Resonance.}

The 1H NMR and 13C NMR techniques play an important role in the identification of complex structures. As mentioned above, hydrogen bonds rather than chemical bonds create interactions between polyphenols and phospholipids. 


\subsubsection{HNMR}

The 1H-NMR signal originating from the atoms involved in the creation of the complex is markedly modified in nonpolar solvents without any summation of the signal unique to the individual molecules. The signs that the proton cannot be relieved should be broadened from the protons belonging to the flavonoids. In phospholipids, all the signals are enlarged when an uplift shift is experienced by the singlet corresponding to the $\mathrm{N}-(\mathrm{CH} 3) 3$ of choline. Heating the sample to 60 results in the emergence of some new large bands, primarily referring to the flavonoid moiety resonance. The NMR spectra of (+)-catechin and its stanchion-metric complex with distearoyl phosphatidyl choline have been studied by Bombardelli et al., 41,96

\subsubsection{CNMR.}

In the 13C-NMR spectrum of (+) - catechin and its stoichiometric complex with distearoyl phosphatidylcholine, in particular when recorded at room temperature in C6D6, all flavonoid carbons are clearly invisible. The signals corresponding to the lipid portion of glycerol and choline (between 60-80 ppm) are broadened and some are moved, although most of the fatty acid chains' resonances maintain their original sharp line form. After heating to $600 \mathrm{c}$, all the signals belonging to the flavonoid bands reappear, even though they are still very wide and partially overlapping. Based on NMR results, Angelico et al. identified that hydrogen bonds between some polar phenolic functional groups of silybin $\mathrm{A}$ and phospholipids can form. ${ }^{97}$ The spectra of different complexes of phyto-phospholipids indicate that the hydrophobic side of lipids will act on the central choline-bioactive portions of these complexes to cover the envelope.

\section{6 (FTIR) Fourier transform infrared spectroscopy.}

Infrared (IR) spectroscopy, comparing the spectrum of the complex with the spectrum of the individual components and their mechanical mixtures, will confirm the formation of the complex. FTIR spectroscopy is also a useful tool for controlling the stability of phytosomes when microdispersed in water or when incorporated in a very simple cosmetic gel. IR spectrum is an effective tool for structural analysis and generates various functional groups with distinct characteristics of band number, position, shape and intensity. The formation of phyto-phospholipid complexes can be confirmed by comparing the spectroscopy of the phosphatidylcholine complexes with that of the physical mixtures. Mazumdar et al. prepared sinigrin-phytosome complexes, the phytosome complex FTIR showed different peaks from sinigrin, phospholipids and their mechanical mixture. ${ }^{89}$ Rathee $\mathrm{S}$ and Kamboj A, prepared phytophospholipoid complex form Citrullus colocynth (L.), Momordica balsa mina and Momordica dioica. The conformation of complex take place by using FTIR spectroscopy. 98

\subsection{X-ray diffraction (XRD).}

XRD analysis can investigate the structure of crystalline materials, including atomic arrangement, crystalline size, and imperfections. Results using a Phillips X-Ray diffractometer (Model 1130/90) with a graphite monochrome at a count rate of $103 .{ }^{99}$ Currently, X-ray diffraction is an effective method for examining the microstructure of both crystalline forms and some amorphous. X-ray diffraction is typically performed on either active constituents or active constituents of phytophospholipid complexes, PCs and their physical mixtures. Das MK and Kalita B. performed phytophospholipid complexes (phytosomes) of rutin for transdermal application. XRD was done on pure Rutin and RN-Ps in different ratios of drug and PC to see the crystallinity in the substance. Sample was scanned in the angular range of $50-800$ in a PHILIPS XPert Pro X-Ray Diffractometer. Dried powder sample was kept in sample holder $(20 \mathrm{~mm} \times 15 \mathrm{~mm} \times 2 \mathrm{~mm})$ which was fitted into the instrument and X-ray was passed through the sample. ${ }^{60}$

\subsection{Entrapment Efficiency.}

The entrapment efficiency of nanocarriers can be calculated using a direct or indirect method. In the indirect method, the unrestricted or free amount was estimated in the supernatant after centrifugation. ${ }^{100}$ The entrapment efficiency or percentage of the content was estimated to be the difference between the initial amount of the drug and the free or unentrapped amount of the drug in the supernatant with respect to the total amount incorporated in the nanocarrier preparation. However, in the direct method, nanocarriers have been solubilized in an appropriate solvent and analysed after filtration and an appropriate dilution for the estimation of trapping efficiency by an appropriate technique. Incorporation efficiency was calculated as a percent drug content using Eq. [1]

Incorporation efficiency = Amount of drug in nanocarriers / Initial amount of drug *100

Sushila Rathee and Anjoo Kamboj are performed phytosome complex entrapment efficiency by using by followed mention method Accurately weighted quantities $(10 \mathrm{mg})$ of complexes were dissolved in methanol. Absorbance was noted at $370 \mathrm{~nm}$ in order to record the concentration of extracts present in the solution. ${ }^{98}$ The total yield of the extracts was therefore calculated and the EE was determined by the following formula:

$$
\begin{gathered}
\text { EE }(\%)=\text { amount of extract in complex/total amount of } \\
\text { extract taken*100 }
\end{gathered}
$$

\subsection{Solubility study.}

The solubility of drug-loaded nanocarriers has been estimated in different solvents with a range of polarity at a certain temperature and the content of the dissolved drug has been measured by the appropriate analytical technique at the maximum absorption observed. ${ }^{101} \mathrm{Li}$ et al. reported an increase in the solubility of ferulic acid using phospholipid complexation. Complex was prepared in different drug-tophospholipid ratios $(2: 1,1: 1,1: 2,1: 3$, and $1: 4)$ using the rotary evaporation method of Soy lecithin. The resulting complex showed a significant improvement in the solubility of ferulic acid from a complex $(0.68 \pm 0.01 \mathrm{mg} / \mathrm{ml})$ to a pure drug $(0.67 \pm 0.02 \mathrm{mg} / \mathrm{ml})$. Enhanced solubility resulted in improved bioavailability and inhibition of cellular melanogenesis activity. ${ }^{102}$

\section{Marketed Products of Phytosomes.}

Today, advanced technology is bringing about a revolution in the pharmaceutical field. The pharmaceutical industry is producing a new drug delivery system for better therapeutic efficacy. Plant active ingredients are now formulated in the form of phytosomes and many products are available on the market. Commercially available registered Phytosomes products by different manufacturers, as summarized in Table 2, claim safe and synergistic therapeutic benefits under different pathological conditions. 
Table 2: Commercially available Phytosomes formulation with various therapeutic applications $38,73,97,103-107$

\begin{tabular}{|c|c|c|}
\hline & Plant source & Pharmacological activity \\
\hline GINSELECT PHYTOSOME ${ }^{\circledR}$ & $\begin{array}{l}\text { Panax ginseng C.A. } \\
\text { Meyer- Root }\end{array}$ & Adaptogen, tonic, Skin tightener. \\
\hline LEUCOSELECT PHYTOSOME ${ }^{\circledR}$ & Vitis vinifera L. - Seed & Antioxidant, UV protectant. \\
\hline VIRTIVA ${ }^{\circledR}$ & Ginkgo biloba L. - Leaf & Cognition Increaser. \\
\hline $\begin{array}{l}\text { VISNADEX }^{\circledR} \\
\text { VISNADIN PHYTOSOME }\end{array}$ & $\begin{array}{l}\text { Ammivisnaga (L.) Lam. - } \\
\text { Umbel without fruits }\end{array}$ & Vasokinetic \\
\hline $\begin{array}{l}\text { CASPEROME }^{\mathrm{TM}} \\
\text { BOSWELLIA PHYTOSOME }^{\circledR}\end{array}$ & $\begin{array}{l}\text { Boswelliaserrata Roxb. } \\
\text { Ex Colebr. - Resin }\end{array}$ & $\begin{array}{l}\text { Anti-inflammatory, } \\
\text { Mitigative }\end{array}$ \\
\hline $\begin{array}{l}\text { DIMERIC FLAVONOIDS } \\
\text { PHYTOSOME }^{\circledR}\end{array}$ & Ginkgo biloba L. - Leaf & $\begin{array}{l}\text { Lipolytic, Vasokinetic, } \\
\text { PDE inhibition }\end{array}$ \\
\hline $\begin{array}{l}\text { CURCUMIN PHYTOSOMETM, } \\
\text { CURCUVET }^{\circledR}\left(\text { MERIVA }^{\circledR}\right)\end{array}$ & Curcuma longa & Anti-inflammatory, osteoarthritis, anticancer \\
\hline GREEN TEA PHYTOSOMETM & Camellia sinensis & $\begin{array}{l}\text { Nutraceutical, anticancer, Antioxidant, atherosclerosis, } \\
\text { hepatoprotective, antidiabetic, anti-inflammatory }\end{array}$ \\
\hline ECHNIACEA PHYTOSOMETM & Echniacea angustifolia & Nutraceutical, immunomodulatory. \\
\hline ZANTHALENE PHYTOSOMETM & Zanthoxylum bungeanum & Soothing and Anti-reddening. \\
\hline SERICOSIDE & Terminalia serica & Anti-aging, skin restructuring. \\
\hline VITABLUE PHYTOSOMETM & Vaccinium angustifolium & Anti-oxidant, improves vision, memory enhancer. \\
\hline $\begin{array}{l}\text { ESCIN ß SITOSTEROL, } \\
\text { PHYTOSOMETM }\end{array}$ & Aesculus hippocastanum & Anti-oedema and vasoactive properties \\
\hline NARINGENIN PHYTOSOMETM & Citrus aurantium & Antioxidant \\
\hline $\begin{array}{l}\text { SILYBIN PHYTOSOMETM } \\
\text { (SILIPHOS } ®)\end{array}$ & Silybium maranium & Hepatoprotective, hepatitis, cirrhosis and Inflammation. \\
\hline
\end{tabular}

\section{Recent patents on Phytosome.}

Table 2: Example of Recent patents approved on phytosome

\begin{tabular}{|l|l|c|}
\hline Patent No. & Title of Patent & Ref \\
\hline EP/1844785 & Phospholipid complexes of olive fruits or leaves extracts having improved bioavailability & 108 \\
\hline US 7691422 & Oral compositions for the treatment of cellulite & 109 \\
\hline EP1813280 & $\begin{array}{l}\text { Compositions comprising Ginkgo biloba derivatives for the treatment of asthmatic and } \\
\text { allergic conditions. }\end{array}$ & 110 \\
\hline WO 2007/101551 & Phospholipid complexes of curcumin having improved bioavailability & 111 \\
\hline US/2007/ 0015698 & Treatment of skin, and wound repair, with thymosin $\beta 4$ & 112 \\
\hline EP1640041 & Cosmetic and dermatological composition for the treatment of aging or photo damaged skin. & 113 \\
\hline EP1690862 & $\begin{array}{l}\text { Fatty acid monoesters of sorbityl furfural and compositions for cosmetic and dermatological } \\
\text { use. }\end{array}$ & 113 \\
\hline EP0283713 & $\begin{array}{l}\text { Compositions containing a phospholipid-curcumin complex and piperine } \\
\text { sensitizing agent }\end{array}$ & 114 \\
\hline WO/2004/045 541 & Shemo & 115 \\
\hline EP 0464297 & $\begin{array}{l}\text { Soluble isoflavone phytosomal compositions } \\
\text { thereof and pharmaceutical and cosmetic formulations containing them. }\end{array}$ & 111 \\
\hline EP 0441279 & Bilobalide phospholipid complexes, their applications and formulations containing them & 117 \\
\hline
\end{tabular}




\section{Future perspectives.}

The method of complexing herbal active ingredients with dietary phospholipids has emerged as a prominent method for enhancing the pharmacokinetic and pharmacodynamic profiles of phytoconstituents with massive therapeutic potential but with poor bioavailability. The phytophospholipid complex which had been initially developed for its cosmetic application has now been extensively researched and developed as a novel drug carrier for systemic action. Although the field is being explored to a large extent, the scope of the research needs to be broadened to address the issues of the preparation technique, stability and actual clinical superiority of these drug delivery systems. A detailed inspection of published literature reveals that extensive research is ongoing in the field of novel drug delivery and focuses on herbal active ingredients and extracts. It is well known that several plant extracts and their constituents have significant pharmacological or beneficial effects on health. Researchers should pay more attention to carrier systems for the efficient delivery of these plant components/extracts, which can significantly improve the therapeutic capacity of delivery systems. These plant constituents/extracts may be complexed with phospholipids for the efficient systematic delivery of herbal constituents.

The solvent evaporation technique has frequently been used as a conventional method for the formulation of phytophospholipid complexes. However, the process involves a number of processing steps that are timeconsuming and the quality of the final product in terms of particle size, morphology and hygroscopicity often depends on the method used to dry the residues that it has not been optimized in any of the studies. In order to overcome the drawbacks of conventional methods, the supercritical fluid technique can be incorporated, as the particle size and distribution can be more precisely controlled under very mild temperature conditions. The uniformity of the particle size further improves the systemic bioavailability. The CO2 supercritical fluid is non-hazardous and provides stable inert conditions for sensitive drug candidates. There is a lack of research data to support this argument and further work needs to be done on formulation optimisation using the supercritical fluid technique and its impact on the in vivo parameters of herbal drugs. Most of the research work has been done on the use of drugs and phospholipids in a 1:1 molar ratio by convention. However, numerous research findings suggest that a drug to phospholipid ratio other than 1:1 produces a better product in terms of physiological and pharmacological properties. The yield of phytophospholipid complexes varied significantly from about $25 \%$ to more than $90 \%$ in different studies and was attributed to different formulation factors, such as drug-to-phospholipid ratio, temperature and duration of treatment, which have been shown to affect the yield of the carrier system. ${ }^{44,102}$

Practical yield and drying of phytophospholipid complexes are another challenge facing scientists. Yield varies by method of preparation and is not easily reproducible. Factors such as processing time, the ratio of plant extract to phospholipid and the temperature maintained during the process determine the quality and yield of the product. The statistical technique used may be a tool for the design of a specified proportions between plant extracts and phospholipids, along with many other parameters such as temperature and drying time, to achieve maximum trapping efficiency and a superior quality product with the intended drug release profile.
Apart from passive targeting, phytophospholipid complexes could also be ideal candidates for targeted delivery by binding the cellular structures to targeting receptors and antigens. This will further broaden the scope of use of phytophospholipid complexes in the treatment of numerous debilitating disorders like rheumatoid arthritis, osteoporosis and melanoma.

\section{CONCLUSION}

The phytophospholipid complex formation methodology provided an excellent opportunity and hope to improve the in vivo bioavailability of herbal drugs which, despite positive in vitro results, can't produce a similar in vivo response. Polyphenolic constituents of plants such as flavones and many others have enormous medical applications, but due to their inability to cross the lipid barrier their use in the treatment of serious diseases such as cancer, hepatic diseases and rheumatoid arthritis conditions has remained unsolved uneasiness for quite a long period of time. Introduction into dietary phospholipids such as Phytosome ${ }^{\circledR}$ has effectively addressed this issue and has offered the preparation of herbal drugs with adequate lipid penetrability, higher concentration and sustained therapeutic levels in plasma at a slower rate of elimination. Phospholipids show affinity to bioactive compounds through hydrogen bond interactions. Theoretically, a phospholipid complex strategy should be appropriate for any bioactive component not limited to flavonoids. With advances in research, we are updating the latest advances in phospholipids, phyto-active constituents, solvents and stoichiometric ratios that are vital for the preparation of phospholipids complexes.

A higher amount of active drug has been made available at the Phytosome site of action. Many effective phytocomponents are now on the market with better bioavailability in the form of phytosomes. Evaluation and structural confirmation of phospholipid complexes has been well established. Bioavailability can be substantially enhanced with the help of phospholipids compared to chemically equivalent non-complex forms. The potential of phytophospholipid complexes, with the efforts of clinicians and other scientists, has a great future for pharmaceutical applications.

\section{Funding Sources}

There is no funding source for this article.

\section{Declaration of conflicts interest}

The authors report no conflicts of interest. The authors alone are responsible for the content and writing of this article.

\section{Acknowledgments}

This review did not receive any specific grant from funding agencies in the public, commercial, or not-for-profit sectors.

\section{REFERENCES}

1. Pawar, H. A.; Bhangale, B. D., Phytosome as a novel biomedicine: a microencapsulated drug delivery system. $J$ Bioanal Biomed 2015, 7 (1), 6-12.

2. Li, J.; Wang, X.; Zhang, T.; Wang, C.; Huang, Z.; Luo, X.; Deng, Y., A review on phospholipids and their main applications in drug delivery systems. Asian journal of pharmaceutical sciences 2015, 10 (2), 81-98.

3. Allen, T. M.; Cullis, P. R., Liposomal drug delivery systems: from concept to clinical applications. Advanced drug delivery reviews 2013, 65 (1), 36-48.

4. Hippalgaonkar, K.; Majumdar, S.; Kansara, V., Injectable lipid emulsions-advancements, opportunities and challenges. Aaps Pharmscitech 2010, 11 (4), 1526-1540. 
5. Rupp, C.; Steckel, H.; Müller, B. W., Solubilization of poorly water-soluble drugs by mixed micelles based on hydrogenated phosphatidylcholine. International journal of pharmaceutics 2010, 395 (1-2), 272-280.

6. Bhattacharya, S., Phytosomes: the new technology for enhancement of bioavailability of botanicals and nutraceuticals. International Journal of Health Research 2009, 2 (3), 225-232.

7. Khan, M. S.; Krishnaraj, K., Phospholipids: a novel adjuvant in herbal drug delivery systems. Critical Reviews ${ }^{T M}$ in Therapeutic Drug Carrier Systems 2014, 31 (5).

8. Lu, M.; Qiu, Q.; Luo, X.; Liu, X.; Sun, J.; Wang, C.; Lin, X.; Deng, Y.; Song, Y., Phyto-phospholipid complexes (phytosomes): A novel strategy to improve the bioavailability of active constituents. Asian journal of pharmaceutical sciences 2019, 14 (3), 265-274.

9. Suriyakala, P.; Babu, N. S.; Rajan, D. S.; Prabakaran, L., Phospholipids as versatile polymer in drug delivery systems. Int J Pharm Pharm Sci 2014, 6 (1), 8-11.

10. Berridge, M. J.; Irvine, R. F., Inositol phosphates and cell signalling. Nature 1989, 341 (6239), 197-205.

11. Baer, E.; Pavanaram, S. K., N-Methylcephalins I. Synthesis of distearoyl l- $\alpha$-glycerylphosphoryl-(n-methyl) ethanolamine. Journal of Biological Chemistry 1961, 236 (5), 1269-1272.

12. Tao, B. Y., Industrial applications for plant oils and lipids. In Bioprocessing for value-added products from renewable resources, Elsevier: 2007; pp 611-627.

13. McIntosh, T. J.; Simon, S. A.; Needham, D.; Huang, C. H., Structure and cohesive properties of sphingomyelin/cholesterol bilayers. Biochemistry 1992, 31 (7), 2012-2020.

14. Testi, R., Sphingomyelin breakdown and cell fate. Trends in biochemical sciences 1996, 21 (12), 468-471.

15. Brügger, B.; Sandhoff, R.; Wegehingel, S.; Gorgas, K.; Malsam, J.; Helms, J. B.; Lehmann, W.-D.; Nickel, W.; Wieland, F. T. Evidence for segregation of sphingomyelin and cholesterol during formation of COPI-coated vesicles. The Journal of cell biology 2000, 151 (3), 507-518.

16. Van Hoogevest, P.; Wendel, A., The use of natural and synthetic phospholipids as pharmaceutical excipients. European journal of lipid science and technology 2014, 116 (9), 1088-1107.

17. Baer, E., From the trioses to the synthesis of natural phospholipids: A research trail of forty years. Journal of the American Oil Chemists' Society 1965, 42 (4), 257-266.

18. Shurtleff, W.; Aoyagi, A., History of Lecithin and Phospholipids (1850-2016): Extensively Annotated Bibliography and Sourcebook, Including Phosphatides and Liposomes. Soyinfo Center: 2016.

19. Guideline, I. H. T., Impurities: Guideline for residual solvents Q3C (R5). Current Step 2005, 4, 1-25.

20. Aluko, R. E.; Mine, Y., Characterization of oil-in-water emulsions stabilized by hen's egg yolk granule. Food Hydrocolloids 1998, 12 (2), 203-210.

21. Senior, J.; Gregoriadis, G., Stability of small unilamellar liposomes in serum and clearance from the circulation: the effect of the phospholipid and cholesterol components. Life sciences 1982, 30 (24), 2123-2136.

22. Dhandapani, R.; Sabna, B., Phytochemical constituents of some Indian medicinal plants. Ancient science of life 2008, 27 (4), 1.

23. Okwu, D., Evaluation of chemical composition of indeginous species and flavouring agents. Global Journal of Pure and Applied Sciences 2001, 7 (3), 455-460.

24. Kidd, P. M., Bioavailability and activity of phytosome complexes from botanical polyphenols: the silymarin, curcumin, green tea, and grape seed extracts. Altern Med Rev 2009, 14 (3), 226-46.

25. Zhang, X.; Zhang, Y.; Guo, S.; Bai, F.; Wu, T.; Zhao, Y., Improved oral bioavailability of 20 (R)-25-methoxyl-dammarane-3 $\beta$, $12 \beta, 20$-triol using nanoemulsion based on phospholipid complex: design, characterization, and in vivo pharmacokinetics in rats. Drug design, development and therapy 2016, 10, 3707.

26. Parry, M. J.; Alakoskela, J.-M. I.; Khandelia, H.; Kumar, S. A.; Jäättelä, M.; Mahalka, A. K.; Kinnunen, P. K., High-affinity small molecule- phospholipid complex formation: binding of siramesine to phosphatidic acid. Journal of the American Chemical Society 2008, 130 (39), 12953-12960.
27. Ghanbarzadeh, B.; Babazadeh, A.; Hamishehkar, H., Nanophytosome as a potential food-grade delivery system. Food bioscience 2016, 15, 126-135.

28. Dewanjee, S.; Gangopadhyay, M.; Bhattacharya, N.; Khanra, R. Dua, T. K., Bioautography and its scope in the field of natural product chemistry. Journal of Pharmaceutical Analysis 2015, 5 (2), 75-84

29. Permana, A. D.; Utami, R. N.; Courtenay, A. J.; Manggau, M. A.; Donnelly, R. F.; Rahman, L., Phytosomal nanocarriers as platforms for improved delivery of natural antioxidant and photoprotective compounds in propolis: An approach for enhanced both dissolution behaviour in biorelevant media and skin retention profiles. Journal of Photochemistry and Photobiology B: Biology 2020, 205, 111846.

30. Khan, J.; Alexander, A.; Saraf, S.; Saraf, S., Recent advances and future prospects of phyto-phospholipid complexation technique for improving pharmacokinetic profile of plant actives. Journal of controlled release 2013, 168 (1), 50-60.

31. Shakeri, A.; Sahebkar, A., Phytosome: a fatty solution for efficient formulation of phytopharmaceuticals. Recent Patents on Drug Delivery and Formulation 2016, 10 (1), 7-10.

32. Patel, J.; Patel, R.; Khambholja, K.; Patel, N., An overview of phytosomes as an advanced herbal drug delivery system. Asian J Pharm Sci 2009, 4 (6), 363-371.

33. Semalty, A., Cyclodextrin and phospholipid complexation in solubility and dissolution enhancement: a critical and metaanalysis. Expert opinion on drug delivery 2014, 11 (8), 12551272.

34. Pathan, R. A.; Bhandari, U., Preparation \& characterization of embelin-phospholipid complex as effective drug delivery tool. Journal of Inclusion Phenomena and Macrocyclic Chemistry 2011, 69 (1), 139-147.

35. Maryana, W.; Rachmawati, H.; Mudhakir, D., Formation of phytosome containing silymarin using thin layer-hydration technique aimed for oral delivery. Materials Today: Proceedings 2016, 3 (3), 855-866.

36. Bombardelli, E.; Curri, S.; Della Loggia, R.; Del Negro, P.; Gariboldi, P.; Tubaro, A., Complexes between phospholipids and vegetal derivates of biological interest. 1989.

37. Alam, M. A.; Al-Jenoobi, F. I.; Al-Mohizea, A. M., Commercially bioavailable proprietary technologies and their marketed products. Drug Discovery Today 2013, 18 (19-20), 936-949.

38. Udapurkar, P.; Bhusnure, O.; Kamble, S.; Biyani, K., Phytophospholipid complex vesicles for phytoconstituents and herbal extracts: A promising drug delivery system. Int J Herbal Med 2016, 4 (5), 14-20.

39. Tripathy, S.; Patel, D. K.; Barob, L.; Naira, S. K., A review on phytosomes, their characterization, advancement \& potential for transdermal application. Journal of Drug Delivery and Therapeutics 2013, 3 (3), 147-152.

40. Semalty, A.; Semalty, M.; Rawat, M. S. M.; Franceschi, F., Supramolecular phospholipids-polyphenolics interactions: The PHYTOSOME® strategy to improve the bioavailability of phytochemicals. Fitoterapia 2010, 81 (5), 306-314.

41. Saurabh, K. V.; Kesari, A., Herbosome a novel carrier for herbal drug delivery. Int J Curr Pharm Res 2011, 3 (3), 36-41.

42. Minakshi, M.; Mulch, S.; Deul, K.; Nayna, M. J., Herbosomes: herbo-phospholipid complex an approach for absorption enhancement. J. Incl. Phenom. Macrocycl. Chem 2011, 69, 139147.

43. Zhang, K.; Zhang, M.; Liu, Z.; Zhang, Y.; Gu, L.; Hu, G.; Chen, X.; Jia, J., Development of quercetin-phospholipid complex to improve the bioavailability and protection effects against carbon tetrachloride-induced hepatotoxicity in SD rats. Fitoterapia 2016, 113, 102-109.

44. Yue, P.-F.; Yuan, H.-L.; Li, X.-Y.; Yang, M.; Zhu, W.-F., Process optimization, characterization and evaluation in vivo of oxymatrine-phospholipid complex. International journal of pharmaceutics 2010, 387 (1-2), 139-146.

45. Bhosale, A. P.; Patil, A.; Swami, M., Herbosomes as a novel drug delivery system for absorption enhancement. World Journal of Pharmacy and Pharmaceutical Sciences 2015, 5 (1), 345-355.

46. Yadav, S. K., Nanoscale Materials in Targeted Drug Delivery, Theragnosis and Tissue Regeneration. Springer: 2016.

47. Kareparamban, J. A.; Nikam, P. H.; Jadhav, A. P.; Kadam, V. J., Phytosome: a novel revolution in herbal drugs. IJRPC 2012, 2 (2), 299-310. 
48. Patel, C. J.; Tyagi, S.; Pinkesh, P.; Yadav, A., Phytosomes: a current trend for enhancement of bioavailability of polar phytoconstituents. Research Journal of Pharmaceutical Dosage Forms and Technology 2014, 6 (1), 44.

49. Amit, P.; Tanwar, Y.; Rakesh, S.; Poojan, P., Phytosome: Phytolipid drug delivery system for improving bioavailability of herbal drug. J Pharm Sci Biosci Res 2013, 3 (2), 51-57.

50. Mauri, P.; Simonetti, P.; Gardana, C.; Minoggio, M.; Morazzoni, P.; Bombardelli, E.; Pietta, P., Liquid chromatography/atmospheric pressure chemical ionization mass spectrometry of terpene lactones in plasma of volunteers dosed with Ginkgo biloba L. extracts. Rapid Communications in Mass Spectrometry 2001, 15 (12), 929934.

51. Murugan, V.; Mukherjee, K.; Maiti, K.; Mukherjee, P. K., Enhanced oral bioavailability and antioxidant profile of ellagic acid by phospholipids. Journal of agricultural and food chemistry 2009, 57 (11), 4559-4565.

52. Patil, M.; Patil, S.; Chittam, K.; Wagh, R., Phytosomes: novel approach in herbal medicines. Asian J Pharm Sci Res 2012, 2, 1-9.

53. Franceschi, F.; Giori, A., Phospholipid complexes of olive fruits or leaves extracts having improved bioavailability. Google Patents: 2007.

54. Sikarwar, M. S.; Sharma, S.; Jain, A. K.; Parial, S., Preparation, characterization and evaluation of marsupsin-phospholipid complex. Aaps Pharmscitech 2008, 9 (1), 129-137.

55. Li, Y.; Yang, D.-J.; Chen, S.-L.; Chen, S.-B.; Chan, A. S.-C., Process parameters and morphology in puerarin, phospholipids and their complex microparticles generation by supercritical antisolvent precipitation. International journal of pharmaceutics 2008, 359 (1-2), 35-45.

56. Ajazuddin; Alexander, A.; Khan, J.; Giri, T. K.; Tripathi, D. K.; Saraf, S.; Saraf, S., Advancement in stimuli triggered in situ gelling delivery for local and systemic route. Expert opinion on drug delivery 2012, 9 (12), 1573-1592.

57. Saoji, S. D.; Raut, N. A.; Dhore, P. W.; Borkar, C. D Popielarczyk, M.; Dave, V.S., Preparation and evaluation of phospholipid-based complex of standardized centella extract (SCE) for the enhanced delivery of phytoconstituents. The AAPS journal 2016, 18 (1), 102-114.

58. Freag, M. S.; Elnaggar, Y. S.; Abdallah, O. Y., Lyophilized phytosomal nanocarriers as platforms for enhanced diosmin delivery: optimization and ex vivo permeation. International journal of nanomedicine 2013, 8, 2385.

59. Zhang, Z.; Chen, Y.; Deng, J.; Jia, X.; Zhou, J.; Lv, H., Solid dispersion of berberine-phospholipid complex/TPGS 1000/SiO2: preparation, characterization and in vivo studies. International journal of pharmaceutics 2014, 465 (1-2), 306316.

60. Das, M. K.; Kalita, B., Design and evaluation of phytophospholipid complexes (phytosomes) of rutin for transdermal application. J Appl Pharm Sci 2014, 4 (10), 051-7.

61. Telange, D. R.; Patil, A. T.; Pethe, A. M.; Fegade, H.; Anand, S.; Dave, V. S., Formulation and characterization of an apigeninphospholipid phytosome (APLC) for improved solubility, in vivo bioavailability, and antioxidant potential. European Journal of Pharmaceutical Sciences 2017, 108, 36-49.

62. Hikino, H.; Kiso, Y.; Wagner, H.; Fiebig, M., Antihepatotoxic actions of flavonolignans from Silybum marianum fruits. Planta medica 1984, 50 (03), 248-250.

63. Wellington, K.; Jarvis, B., Silymarin: a review of its clinical properties in the management of hepatic disorders. BioDrugs 2001, 15 (7), 465-489.

64. Carini, F.; Bartolucci, E.; Cristallini, E., L'impiego della silimarina nel trittamento della steatosi epatica alcoolica. Clin Ter 1985, 114, 307-14.

65. Salmi, H.; Sarna, S., Effect of silymarin on chemical, functional, and morphological alterations of the liver: a double-blind controlled study. Scandinavian journal of gastroenterology 1982, 17 (4), 517-521.

66. Ferenci, P.; Dragosics, B.; Dittrich, H.; Frank, H.; Benda, L.; Lochs, H.; Meryn, S.; Base, W.; Schneider, B., Randomized controlled trial of silymarin treatment in patients with cirrhosis of the liver. Journal of hepatology 1989, 9 (1), 105113

67. Canty, D. J.; Zeisel, S. H., Lecithin and choline in human health and disease. Nutrition reviews 1994, 52 (10), 327-339.
68. Lieber, C. S.; Decarli, L. M.; Mak, K. M.; Kim, C. I.; Leo, M. A., Attenuation of alcohol-induced hepatic fibrosis by polyunsaturated lecithin. Hepatology 1990, 12 (6), 13901398.

69. Aleynik, S. I.; Leo, M. A.; Ma, X.; Aleynik, M. K.; Lieber, C. S., Polyenylphosphatidylcholine prevents carbon tetrachlorideinduced lipid peroxidation while it attenuates liver fibrosis. Journal of hepatology 1997, 27 (3), 554-561.

70. Khan, J.; Saraf, S.; Saraf, S., Preparation and evaluation of luteolin-phospholipid complex as an effective drug delivery tool against GalN/LPS induced liver damage. Pharmaceutical development and technology 2016, 21 (4), 475-486.

71. Valenzuela, A.; Aspillaga, M.; Vial, S.; Guerra, R., Selectivity of silymarin on the increase of the glutathione content in different tissues of the rat. Planta medica 1989, 55 (05), 420 422.

72. Kidd, P. M., Phosphatidylcholine, a superior protectant against liver damage. Altern Med Rev 1996, 1 (4), 258-74.

73. Yanyu, X.; Yunmei, S.; Zhipeng, C.; Qineng, P., The preparation of silybin-phospholipid complex and the study on its pharmacokinetics in rats. International Journal of Pharmaceutics 2006, 307 (1), 77-82.

74. Awasthi, R.; Kulkarni, G.; Pawar, V. K., Phytosomes: an approach to increase the bioavailability of plant extracts. International journal of pharmacy and pharmaceutical sciences 2011, 3 (2), 1-3.

75. Hao, H.; Jia, Y.; Han, R., Phytosomes: an effective approach to enhance the oral bioavailability of active constituents extracted from plants. Journal of Chinese Pharmaceutical Sciences 2013, 22 (5), 385.

76. TOGNI, S.; MARAMALDI, G.; PAGIN, I.; CATTANEO, R.; EGGENHOFFNER, R.; GIACOMELLI, L., Quercetin-phytosome $2 \%$ cream: evaluation of the potential photoirritant and sensitizing effects. Esperienze Dermatol 2016, 18, 85-87.

77. Damle, M.; Mallya, R., Development and evaluation of a nove delivery system containing phytophospholipid complex for skin aging. AAPS PharmSciTech 2016, 17 (3), 607-617.

78. Panda, V. S.; Naik, S. R., Evaluation of cardioprotective activity of Ginkgo biloba and Ocimum sanctum in rodents. Alternative Medicine Review 2009, 14 (2), 161.

79. Morazzoni, P.; Petrini, O.; Scholey, A.; Kennedy, D., Use of a Ginkgo complexes for the enhancement of cognitive functions and the alleviation of mental fatigue. Google Patents: 2013.

80. Kennedy, D.; Haskell, C.; Mauri, P.; Scholey, A., Acute cognitive effects of standardised Ginkgo biloba extract complexed with phosphatidylserine. Human Psychopharmacology: Clinical and Experimental 2007, 22 (4), 199-210.

81. Curri, S.; Bombardelli, E.; Arpaia, G.; Della Loggia, R., Changes in cutaneous precapillary vasomotility induced by topical application of Ginkgo biloba PhytosomeR. 1989.

82. Bombardelli, E.; Curri, S.; Della Loggia, R.; Del Negro, P. Gariboldi, P.; Tubaro, A., Anti-inflammatory activity of 18-ßglycyrrhetinic acid in phytosome form. 1989.

83. Bombardelli, E.; Cristoni, A.; Morazzoni, P., Phytosome® s in functional cosmetics. Fitoterapia (Milano) 1994, 65 (5), $387-$ 401.

84. Pandey, S.; Wu, L.; Guru, S. M.; Buyya, R. In A particle swarm optimization-based heuristic for scheduling workflow applications in cloud computing environments, 2010 24th IEEE international conference on advanced information networking and applications, IEEE: 2010; pp 400-407.

85. Bombardelli, E.; Sabadie, M., Phospholipid complexes of extracts of vitis vinifera, their preparation process and pharmaceutical and cosmetic compositions containing them. Google Patents: 1990.

86. Chen, Z.-p.; Sun, J.; Chen, H.-X.; Xiao, Y.-y.; Liu, D.; Chen, J.; Cai, H.; Cai, B.-c., Comparative pharmacokinetics and bioavailability studies of quercetin, kaempferol and isorhamnetin after oral administration of Ginkgo biloba extracts, Ginkgo biloba extract phospholipid complexes and Ginkgo biloba extract solid dispersions in rats. Fitoterapia 2010, 81 (8), 1045-1052.

87. Usman, M.; Ahmad, M.; Madni, A. U.; Asghar, N.; Akhtar, M.; Atif, M., In-vivo Kinetics of Silymarin (Milk Thistle) on healthy male volunteers. Tropical Journal of Pharmaceutical Research 2009, 8 (4). 
88. Gupta, N. K.; Dixit, V., Development and evaluation of vesicular system for curcumin delivery. Archives of dermatological research 2011, 303 (2), 89-101.

89. Mazumder, A.; Dwivedi, A.; Du Preez, J. L.; Du Plessis, J., In vitro wound healing and cytotoxic effects of sinigrinphytosome complex. International journal of pharmaceutics 2016, 498 (1-2), 283-293.

90. Nič, M.; Jirát, J.; Košata, B.; Jenkins, A.; McNaught, A., IUPAC compendium of chemical terminology. IUPAC, Research Triagle Park, NC 2009.

91. Lowry, G. V.; Hill, R. J.; Harper, S.; Rawle, A. F.; Hendren, C. O.; Klaessig, F.; Nobbmann, U.; Sayre, P.; Rumble, J., Guidance to improve the scientific value of zeta-potential measurements in nanoEHS. Environmental Science: Nano 2016, 3 (5), 953965.

92. Udapurkar, P. P.; Bhusnure, O. G.; Kamble, S. R., Diosmin Phytosomes: development, optimization and physicochemical characterization. Indian J Pharm Educ Res 2018, 52 (4), S29S36.

93. Williams, D. B.; Carter, C. B., Transmission Electron Microscopy: Spectrometry David B. Williams and C. Barry Cart. IV. Plenum: 1996.

94. Menczel, J. D.; Judovits, L.; Prime, R. B.; Bair, H. E.; Reading, M.; Swier, S., Differential scanning calorimetry (DSC). Thermal analysis of polymers: Fundamentals and applications 2009, 7 239.

95. Singh, C.; Bhatt, T. D.; Gill, M. S.; Suresh, S., Novel rifampicinphospholipid complex for tubercular therapy: synthesis, physicochemical characterization and in-vivo evaluation. International journal of pharmaceutics 2014, 460 (1-2), 220227.

96. Sravanthi, M.; Krishna, J. S., Phytosomes: A novel drug delivery for herbal extracts. International Journal of Pharmaceutical Sciences and Research 2013, 4 (3), 949-959.

97. Angelico, R.; Ceglie, A.; Sacco, P.; Colafemmina, G.; Ripoli, M.; Mangia, A., Phyto-liposomes as nanoshuttles for waterinsoluble silybin-phospholipid complex. International journal of pharmaceutics 2014, 471 (1-2), 173-181.

98. Rathee, S.; Kamboj, A., Optimization and development of antidiabetic phytosomes by the Box-Behnken design. Journal of liposome research 2018, 28 (2), 161-172.

99. Wang, G. C., The utilization of slag in civil infrastructure construction. Woodhead Publishing: 2016.

100. Gaikwad, V. L.; Choudhari, P. B.; Bhatia, N. M.; Bhatia, M. S., Characterization of pharmaceutical nanocarriers: in vitro and in vivo studies. In Nanomaterials for Drug Delivery and Therapy, Elsevier: 2019; pp 33-58.

101. Kürti, L.; Gáspár, R.; Márki, Á.; Kápolna, E.; Bocsik, A.; Veszelka, S.; Bartos, C.; Ambrus, R.; Vastag, M.; Deli, M. A., In vitro and in vivo characterization of meloxicam nanoparticles designed for nasal administration. European Journal of Pharmaceutical Sciences 2013, 50 (1), 86-92.

102. Li, L.; Liu, Y.; Xue, Y.; Zhu, J.; Wang, X.; Dong, Y., Preparation of a ferulic acid-phospholipid complex to improve solubility, dissolution, and B16F10 cellular melanogenesis inhibition activity. Chemistry Central Journal 2017, 11 (1), 1-8.

103. Naik, S. R.; Panda, V. S., Hepatoprotective effect of Ginkgoselect Phytosome $®$ in rifampicin induced liver injurym in rats: Evidence of antioxidant activity. Fitoterapia 2008, 79 (6), 439-445.

104. Panda, V. S.; Naik, S. R., Cardioprotective activity of Ginkgo biloba phytosomes in isoproterenol-induced myocardial necrosis in rats: a biochemical and histoarchitectural evaluation. Experimental and toxicologic pathology 2008, 60 (4-5), 397-404.

105. AGRAWAL, V. K.; GUPTA, A.; CHATURVEDI, S., Improvement In Bioavailability of Class-III Drug: Phytolipid Delivery System. Int J Pharm Pharm Sci 2012, 4 (1), 37-42.

106. Karole, S.; Gupta, G., Preparation and evaluation of phytosomes containing ethanolic extract of leaves of Bombax ceiba for hepatoprotective activity. Evaluation 2019, 6 (2), 15.

107. Ittadwar, P. A.; Puranik, P. K., Novel umbelliferone phytosomes: development and optimization using experimental design approach and evaluation of photoprotective and antioxidant activity. Int. J. Pharm. Pharm. Sci 2017, 9, 218-228.

108. Sriya, K. C.; Sai, D.; Sankar, P. R., Phytosomes: A Novel Approach for Herbal Phytochemicals for Enhancing the Bioavailability.

109. Anjana, R.; Kumar, S.; Sharma, H.; Khar, R., Phytosome drug delivery of natural products: A promising technique for enhancing bioavailability. International Journal of Drug Delivery Technology 2017, 7 (03), 157-165.

110. Prasad, S. B.; Bhatia, S.; Singh, S., Phytosome: Phytoconstituent based lipid derived drug delivery system. J Chem Pharm Res 2016, 8 (5), 664-7.

111. Kalita, B.; Das, M. K.; Sharma, A. K., Novel phytosome formulations in making herbal extracts more effective. $J$ Pharm Technol 2013, 6 (11), 1295-1301.

112. Sanghi, D.; Tiwle, R., Herbal drugs an emerging tool for novel drug delivery systems. Asian Journal of Research in Chemistry 2013, 6 (9), 962.

113. Khar, R.; Chakraborthy, G.; Saurabh, M., Phytosomes: a brief overview. Journal of Pharmaceutical Research 2016, 15 (2), 56-62.

114. Kumar, A.; Kumar, B.; Singh, S.; Kaur, B.; Singh, S., A review on phytosomes: novel approach for herbal phytochemicals. Asian J Pharm Clin Res 2017, 10 (10), 41-47.

115. Pandita, A.; Sharma, P., Pharmacosomes: an emerging novel vesicular drug delivery system for poorly soluble synthetic and herbal drugs. International Scholarly Research Notices 2013, 2013.

116. Nimbalkar, C. K.; Hatware, K., Phytosomes-novel drug delivery system. Indian Journal of Drugs 2017, 5 (1), 16-36.

117. Singh, A.; Saharan, V. A.; Singh, M.; Bhandari, A., Phytosome: drug delivery system for polyphenolic phytoconstituents. Iranian Journal of Pharmaceutical Sciences 2011, 7 (4), 209219. 